Article

\title{
Development and Implementation of a Platform for Public Information on Air Quality, Sensor Measurements, and Citizen Science
}

\author{
Joost Wesseling *, Henri de Ruiter ${ }^{\mathbb{D}}$, Christa Blokhuis, Derko Drukker, Ernie Weijers, \\ Hester Volten, Jan Vonk, Lou Gast, Marita Voogt, Peter Zandveld, Sjoerd van Ratingen and \\ Erik Tielemans
}

\author{
National Institute for Public Health and the Environment (RIVM), P.O. Box 1, \\ 3720 BA Bilthoven, The Netherlands \\ * Correspondence: joost.wesseling@rivm.nl; Tel.: +31-(0)30-274-9111
}

Received: 29 June 2019; Accepted: 30 July 2019; Published: 1 August 2019

\begin{abstract}
The use of low-cost sensors for air quality measurements is expanding rapidly, with an associated rise in the number of citizens measuring air quality themselves. This has major implications for traditional air quality monitoring as performed by Environmental Protection Agencies. Here we reflect on the experiences of the Dutch Institute for Public Health and the Environment (RIVM) with the use of low-cost sensors, particularly $\mathrm{NO}_{2}$ and $\mathrm{PM}_{10} / \mathrm{PM}_{2.5}$-sensors, and related citizen science, over the last few years. Specifically, we discuss the Dutch Innovation Program for Environmental Monitoring, which comprises the development of a knowledge portal and sensor data portal, new calibration approaches for sensors, and modelling and assimilation techniques for incorporating these uncertain sensor data into air pollution models. Finally, we highlight some of the challenges that come with the use of low-cost sensors for air quality monitoring, and give some specific use-case examples. Our results show that low-cost sensors can be a valuable addition to traditional air quality monitoring, but so far, their use in official monitoring has been limited. More research is needed to establish robust calibration methods while ongoing work is also aimed at a better understanding of the public's needs for air quality information to optimize the use of low-cost sensors.
\end{abstract}

Keywords: air quality; low-cost sensors; citizen science; monitoring

\section{Introduction}

Air pollution is regarded as an on-going threat to public health and is linked to an estimated 400,000 premature deaths in the EU each year [1]. Given the complexity and impact of air pollution, the EU has introduced the Air Quality Directives to set limit and target values for concentrations of major air pollutants [2,3]. These directives also prescribe in detail how to measure ambient air quality using standardized reference methods, with well-defined quality requirements. Hence, regulatory monitoring networks are generally strictly regulated and based on a limited number of advanced, quality-assured and therefore costly measurement stations. Due to their low spatial resolution, it is often difficult for regulatory measurement networks to meet all demands from local populations asking for detailed information about pollutants, for instance at their residence [4]. Instead, such information is usually derived from models that come with considerable uncertainties.

As smart technology and Internet of Things (IoT) become more prevalent, there is the promise of low-cost sensors that will enable wide-scale monitoring in dense, supplementary networks $[5,6]$. The growing popularity of small low-cost gas and particle sensors, micro-controllers, and open-source programs will increasingly allow citizens to gather air pollution data. Citizens start to measure air 
quality in their own backyard, form their own neighbor watch, and reach out to Environmental Protection Agencies (EPAs) for knowledge and guidance, but also with their sensor results. Many examples of citizen scientists measuring air pollutants already exist [7]. An example of a large-scale and successful citizen science project is Luftdaten [8]. This project started by the Open Knowledge Lab at the local level in Stuttgart (Germany), is now supported in seven languages and has participants from all over the world. Similarly, inspired by technological advancements, many municipalities work on the concept of becoming a 'smart city', based on the premise that data collection from all kinds of sources, including sensors, helps to manage cities efficiently.

For authorities and science communities, sensors may provide a low-cost addition, or ultimately even alternative, to the reference and official equivalent measurement methods defined in the European Air Quality Directive (2008/50/EC). Low-costs sensors allow monitoring at a much higher spatial and temporal resolution. In addition, due to their low cost, these monitoring systems become available for other users and uses. For example, when coupled to GPS and/or smartphones, citizens could estimate their exposure when residing in complex urban areas, traffic junctions, street canyons, and other polluted places. However, the increasing interest in low-cost air quality sensors brings, besides major opportunities, also some important challenges. Currently, the quality of sensor measurements is an issue, as performance may vary spatially and temporally [9]. This makes it difficult to interpret sensor data, especially for citizen scientists with limited background and statistical knowledge. Moreover, authorities are quite often concerned that air quality measurements from sensors will be used in legal procedures despite the fact that they lack an official status.

In response to these rapid technological and societal developments, RIVM and the Dutch Ministry for Infrastructure and Water Management have started a program to innovate the national air quality measurement network. This "Innovation Program for Environmental Monitoring (IPEM)" aims to include small sensors, citizen science, and new modelling techniques as an integral part of the monitoring system. The IPEM started in 2016 and runs for approximately five years. The main milestones of the program are depicted in Figure 1. It is anticipated that the current Dutch network for measuring air quality will evolve to a hybrid system of a high-quality reference base supplemented with large amounts of sensor data collected by citizen scientists, municipalities, companies, etc. Ultimately, the aim of the program is a crowdsourced system that provides local communities with detailed environmental data, while simultaneously enriching the national monitoring system. Equally important, this new approach encourages experts to communicate methods and findings in a way that appeals to their citizen audience.

As a national EPA, an important task for RIVM is to remain an independent and impartial judge of air quality findings, irrespective of whether these are obtained by official measurements or by new sensor technology. Consequently, there are a few challenges that apply specifically to EPAs. For example, it might be tempting for EPAs to prioritize the testing of sensors and to wait to engage with citizen scientists until sensors meet official quality criteria and can be used for monitoring. However, to support citizen science and to be able to make good use of the data, an EPA also needs to devise ways to calibrate and employ the data, and build the infrastructure and communications channels to facilitate the citizen science community, while taking into account their needs and feedback. In addition, it might be best for official monitoring purposes when sensor measurements are standardized, i.e. everyone uses the same sensor and measuring procedure. However, this would limit the freedom of citizen scientists and might impede progress as employing a wide range of sensors in the field provides a real-world 'test lab'. Therefore, an EPA needs to balance its own potential preferences with those of a wider range of stakeholders, including stakeholders that are traditionally somewhat out of scope for a national EPA: citizens, municipalities, and enterprises. All this needs to be done while simultaneously performing the traditional EPA tasks, which include many legal obligations. These challenges thus require an approach that is flexible enough to accommodate different users and usages, while at the same time is focused enough to work towards the goal of a system where official measurements and citizens' measurements are combined. 
This paper describes the building blocks of our "Innovation Program for Environmental Monitoring", which consists of the development of a knowledge portal open to contributions from others, new calibration approaches for low-cost and uncertain sensors, a (sensor) data portal with visualizations for citizens and modelling and assimilation techniques for incorporating these uncertain sensor data in air pollution models. Our approach will be illustrated with a few use-case examples. The full technical details of the examples will not be presented in this overview article, but will be described at a later stage.

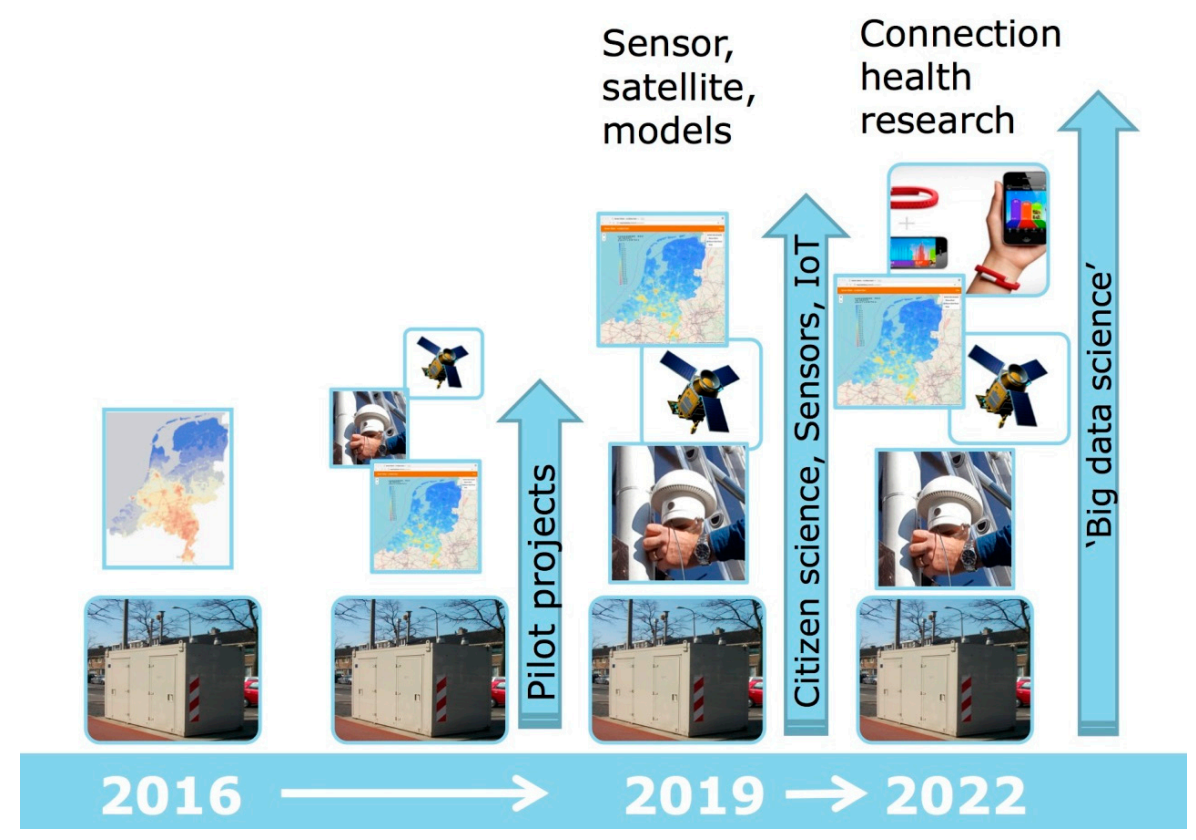

Figure 1. Roadmap of the Dutch Innovation Program for Environmental Monitoring (IPEM) and its associated milestones.

Important scientific questions associated with this innovation program include the overall uncertainty of a large number of low-cost sensors compared to that of the traditional monitoring systems with low spatial resolution, which are discussed conceptually in this paper. Furthermore, we will discuss experiences with citizen science approaches that help EPAs shape new science-society relationships in a more interactive and reflexive way. In doing so, our reflections will help improve understanding of the value of low-cost air quality sensors within the wider context of air quality monitoring and citizen science, and how the role of EPAs might change.

\section{Citizen Science}

The main reason for RIVM's early involvement in citizen science projects was the rapidly developing market for low-cost sensors, which lead to many people measuring air quality in their own backyard. To understand how air quality sensors were being used, it was necessary to engage proactively with existing citizen science communities and to understand their needs. RIVM has therefore been participating in citizen science projects on air quality since 2012. The nature of these early projects, the degree of involvement and collaboration partners have been described in detail elsewhere [10]. Despite the varying nature of these projects, RIVM's main input in these citizen science projects revolved around some common themes, primarily around the need for expert information on questions like:

- What is air quality?

- What are the regulations and policies around air quality?

- How do you measure air quality? What sensors are there on the market? 
- What is the quality of the (sensor) measurements?

- How to put the sensor measurements into a broader context?

These questions overlap with RIVM's core business: the monitoring of air quality. However, to engage constructively with citizen scientists, citizen science groups and local authorities, expert information had to be made easily accessible for citizen scientists. Therefore, a knowledge portal—currently available as "www.samenmeten.nl" (measuring together)—was built to provide the expert information requested by citizen scientists. This knowledge portal was presented at a symposium in December 2016. Attendants at this symposium were citizen scientists, policy makers from the Ministry of Infrastructure and Water Management, local authorities, local health organizations, and specialists from research institutes. The primary aim of the symposium was to exchange information, look for ways to connect and collaborate, and to search for a way forward in citizen science and air quality. Attendance at this first symposium exceeded expectations with more than 100 people present. Many policy makers and specialists were interested in citizen science but did not know exactly how to proceed. Therefore, the community "Measuring Together" was established, with its knowledge portal "samenmeten.nl", as central hub for citizen science and air quality in the Netherlands. This knowledge portal provides information on air quality and sensors, but also on citizen science projects, information usually provided by the projects themselves. At the request of the citizen science community "Measuring Together", RIVM has continued to organize meetings for people to connect and exchange information. Several citizen science meetings were organized with a growing audience, including an international meeting in 2017: "Status of Air Quality Sensors and their use in (official) monitoring strategies" [11].

In short, the air quality citizen science community around "Measuring Together" has been built gradually. First by participating in individual CS projects, by learning from these projects what was needed and by moving forward in small but concrete steps, each time verifying whether the steps were supported by the community.

\section{Example: Succesful Encouragement of Citizen Sensor Use}

RIVM has actively encouraged the use of low-cost sensors in the Netherlands. One successful activity was measuring dust from fireworks during New Year's Eve. This took place for the first time at New Year's Eve 2016/2017. In December 2016, at the end of the first symposium on citizen science and air quality, 65 cheap dust sensors (Shinyei PPD42) were distributed among the audience using a lottery. Participants were instructed to make a weatherproof housing to mount the sensors outside to increase the participant's feeling of ownership and responsibility. Each sensor was already connected to an ESP8266 Wi-Fi communication chip. The results of the measurements were automatically sent to the RIVM data portal where they were visualized. Combined with 25 other similar sensor kits, the effects of fireworks on dust concentrations were measured using a total of 90 cheap dust sensors.

The measurements during New Year's Eve 2016/2017 attracted a lot of media attention. For instance, a newspaper headline read: "Fireworks dust peak finally measured". Although inaccurate, as fireworks dust is measured every year without fail by our colleagues using official reference measurements, this headline is a great illustration of the potential of citizen science measurements to attract attention to air quality issues. The measurements also figured on social media, particularly on Twitter where "Measuring Together" (active as @samenmeten) received messages from several citizen scientists offering data, and embracing the data and posting results faster than we could do ourselves.

Aware of the impact from the 2016/2017 fireworks project, RIVM distributed the next year some 65 more modern dust sensors (Nova SDS011) [12] among several citizen science projects in Dutch cities. By this time, a community of citizens building their own sensor kits had started to grow in the Netherlands, some of which used the Long Range (LoRa) network for acquisition of the data. In total, 150 sensors measured the effects of fireworks on the $\mathrm{PM}_{10}$ and $\mathrm{PM}_{2.5}$ concentrations during New Year 2017/2018. Finally, during New Year's Eve 2018/2019, a thriving community with approximately 350 dust sensors, mostly SDS011, showed how dust concentrations quickly increased after the fireworks started. 
The results from these three measuring campaigns show that sensors registered increases in $\mathrm{PM}_{2.5}$ and $\mathrm{PM}_{10}$ concentrations of factors 16-25 between midday on December 31 and the start of the New Year. After only a few hours, concentrations were back at the same levels as the day before (Figure 2).

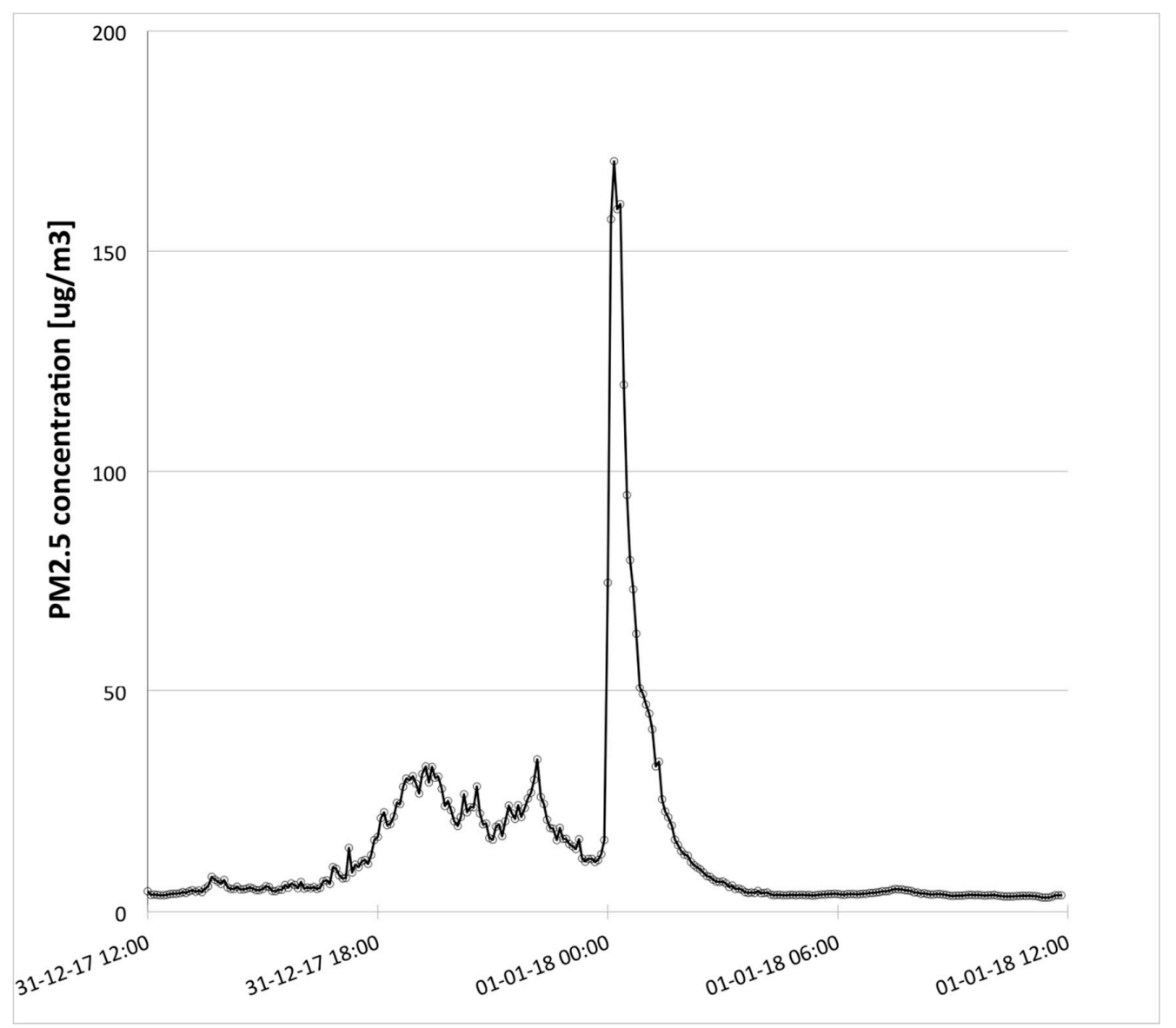

Figure 2. Average PM2.5 concentration measured by approximately 300 dust sensors between 31 December 2017, 12:00 (MET) and 1 January 2018, 12:00 (MET).

All data was instantly shared with both participants and the public. The data was analyzed by both professionals as well as others.

Thus, the Fireworks-project helped to build, unite, and enlarge the air quality citizen science community in the Netherlands. It also further inspired RIVM to build a "Measuring Together" data portal open for all citizen science projects to upload their data, see Section 5.

\section{Calibration of Sensors}

The technological potential of sensors is associated with new challenges: the reliability of the measurement results is often inadequate, even for applications where lower accuracy is sufficient, such as in citizen science projects. RIVM has therefore initiated several studies not only assessing the quality of single sensor data, which are influenced by varying meteorology and possible interfering gasses, but also improving their measuring performance (see below). This is not purely a scientific exercise but takes place in cooperation with citizens, manufacturers and authorities. In the end, this should lead to a selection of (sets of) sensors that can be used in official monitoring and modelling, as well as in other applications like citizen science initiatives. 


\subsection{Calibration of $\mathrm{NO}_{2}$ Sensors}

There are approximately fifty sensor kits with $\mathrm{NO}_{2}$ sensors operating in the Netherlands (status June 2019), with about thirty operated by RIVM. The Alphasense $\mathrm{B} 43 \mathrm{~F} \mathrm{NO}_{2}$ sensor [13] is employed in all of these. To our knowledge, this sensor is one of the few that starts to give sensible results at ambient $\mathrm{NO}_{2}$ levels, presently roughly $15-25 \mu \mathrm{g} / \mathrm{m}^{3}$ (yearly average), although it must be noted that the performance of the sensor is better at higher concentration levels.

Analysis of the results shows that the $\mathrm{NO}_{2}$ sensor can be calibrated successfully using a comparison to reference measurements. Calibration algorithms are derived for individual sensors using multi-linear regression models to account for influences of meteorology and ozone. These are applied real time, using meteorological data and hourly maps of ozone based on a combination of a model and reference measurements. Presently, a relatively simple formula is found to work well to calculate $\mathrm{NO}_{2}$ from the output voltage of the sensor and several environmental parameters:

$$
\text { NO2 }=a 0+a 1 \times V_{\text {sensor }}+a 2 \times \mathrm{O}_{\text {ambient }}+a 3 \times \mathrm{T}_{\text {ambient }}+a 4 \times V_{\text {sensor }} \times \mathrm{O}_{\text {ambient }}
$$

where $\mathrm{NO} 2$ is the $\mathrm{NO}_{2}$ concentration derived from the sensor (in microgram per cubic meter); $V_{\text {sensor }}$ is the output voltage of the sensor (in Volt); $\mathrm{O3}_{\text {ambient }}$ is the ambient ozone concentration at the location of the sensor (in microgram per cubic meter); $T_{\text {ambient }}$ is the ambient temperature at the location of the sensor in ${ }^{\circ} \mathrm{C}$.

The parameters $a 0-a 4$ in Equation (1) are obtained by co-locating the sensors with official measuring equipment, collecting several weeks of data and subsequently fitting the parameters individually using the software packages R (version 3.3.3) [14] and RStudio (version 1.0.136) [15], using the multi-regression routine $\mathrm{lm}$. The result of a co-location experiment comparing a set of eight low-cost sensor systems measuring $\mathrm{NO}_{2}$ with a reference instrument during several weeks is shown in Figure 3. The results of the sensors, after fitting the calibration parameters, follow the result of the official measurements very closely. The correlation coefficients between the individual sensors and the reference measurements shown in Figure 3 are all higher than 0.95 .

However, some of the sensors drift and the sensitivity will change significantly over time. Several calibration strategies are being tested to detect this drift and change in sensitivity, and to correct for it. The simplest method is to re-calibrate each sensor after a specific period in the field, say 2-3 months, but this is less feasible in practice as the number of sensors increases. A slightly more complex method is based on the assumption that during the night there is limited variation in $\mathrm{NO}_{2}$ concentration. During the night, the calibration of the sensors can be verified by comparing the results of sensors to nearby official measurements [16]. If there are no nearby measurements, an interpolation between measurements or model information can be used. When significant differences are observed, nightly concentrations are used to adjust the parameters in the calibration. The 'nightly calibration' not only assumes limited local gradients in $\mathrm{NO}_{2}$ gradients, but also assumes that the effects of diurnal ozone variations are limited. There are substantial uncertainties in these assumptions. However, these uncertainties seem less than there will be in case the sensors are allowed to drift without any adjustment. Tests performed by both RIVM and others indicate that the RMSE between official measurements and co-located sensors after applying the 'nightly calibration' is comparable to that obtained using calibration over the whole period [17].

Preliminary results from measurements obtained with the Alphasense B43F, indicate that calibration and use of these sensors in the winter can result in very stable results, but in the summer the results are rather poor [17]. Possibly the sensor does not perform well at higher temperatures, which might be caused by as of yet unknown interferences, and/or because the $\mathrm{NO}_{2}$ concentrations typically observed during summer lie close to or below the detection limit. 


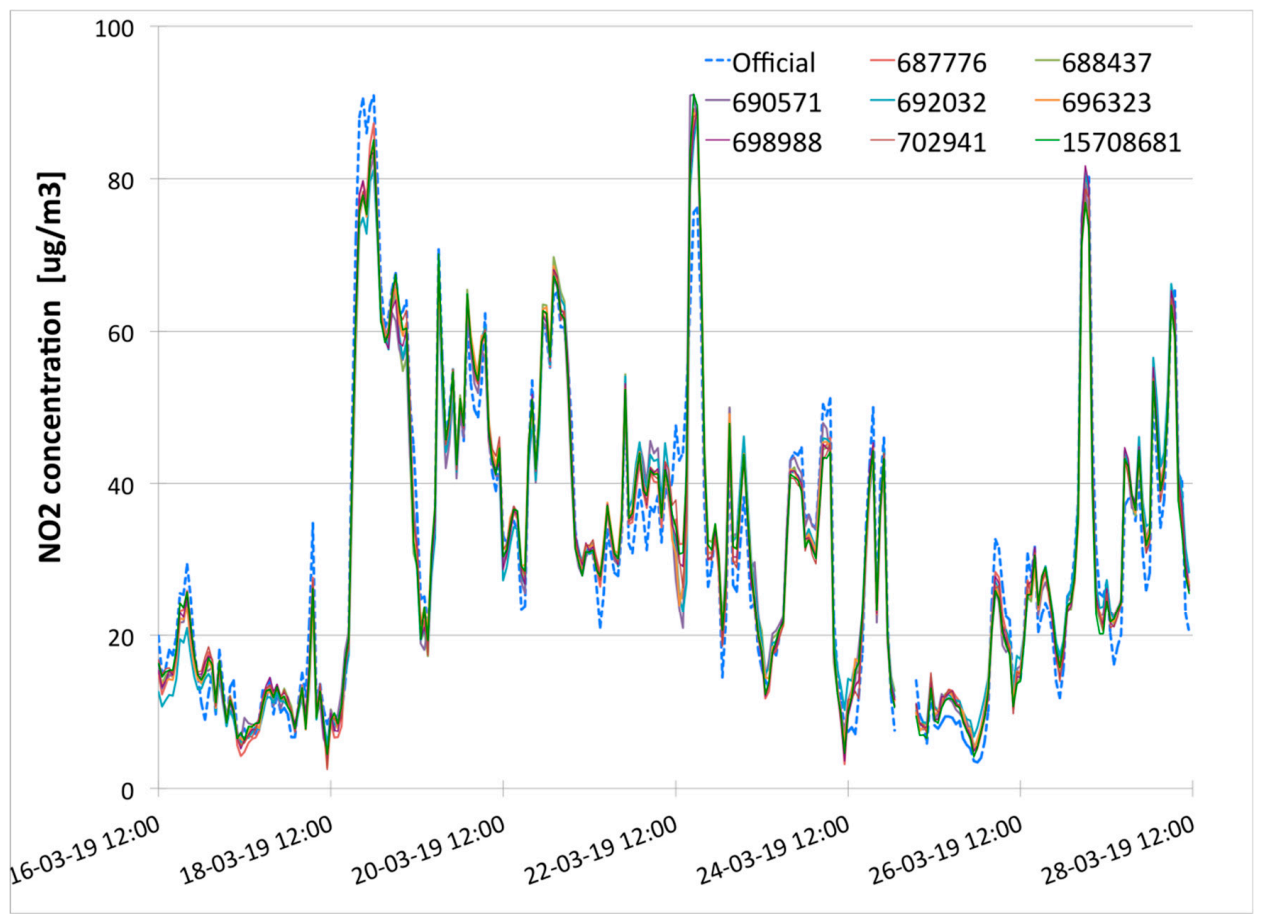

Figure 3. Result of a co-location experiment comparing a set of eight low-cost sensor systems measuring $\mathrm{NO}_{2}$ with a reference instrument, between 3 March 2019 (MET) and 28 March 2019 (MET-DST). The labels of the curves in the figure indicate the results of the official reference measurements and results of the sensors.

\subsection{Calibration of $P M_{2.5} / P M_{10}$ Sensors}

Sensors for particulate matter have their own unique problem: humidity [18]. Dust sensors do not actually measure dust mass but they use an optical system, mostly a laser, to detect the passage of particles [12]. Proprietary algorithms from the manufacturers estimate the number of particles from the optical signals and their estimated sizes. Particle numbers combined with estimates for the average density then provide an estimate of the amount of mass in the air.

When the relative humidity approaches $100 \%$, for example during fog episodes in the morning, the sensors interpret small drops of water as particles, creating concentration peaks. Citizen scientists quite often interpret these peaks as pollution due to the morning rush hour. RIVM has developed an approach to perform a real-time correction for meteorological conditions for (groups of) the Nova SDS011 sensor (see Section 4).

Corrections for sensors can also be obtained by comparing results of sensors to those of nearby official measurements over a long period and subsequently determining empirical relations. This is similar to the procedure used for $\mathrm{NO}_{2}$ sensors, but the relation used for the calibration is different. As a spin-off of the 2017/2018 citizen science measurements of fireworks, a substantial number of SDS011 sensors was operating in the city center of Amsterdam. Combined with a number of sensors in Amsterdam participating in the Luftdaten project, there were some 20 sensors providing data in most or all of 2018. Amsterdam furthermore has a relative dense network of official measurements, maintained by the municipal health service. These measurements are performed using the BAM1020 from Met-One [19]. Based on the official hourly measurements in Amsterdam during all of 2018, is it observed that there are, on average, only relatively small systematic differences between the measurement locations (approximately 15\% for traffic and urban background stations). Although there are marked differences between hourly measurements at various locations, they tend to cancel out with respect to the average concentration in the center of Amsterdam. Therefore, the hourly average of the 20 sensors irrespective of their location was compared to official measurements at a central 
urban background location. The hourly ratios between the official measurements and the sensors were subsequently plotted as a function of the relative humidity, measured at nearby Schiphol airport. A simple relation of the hourly correction factors $(\mathrm{CF})$ emerged:

$$
\mathrm{CF}=a(100-\mathrm{RH})^{b}
$$

With CF the (dimensionless) correction factor and RH the relative humidity (in \%). Using (100-RH) instead of just RH makes it easier to fit a relation. The factor $a$ and power $b$ are fitted from the data using the packages $\mathrm{R}$ and RStudio with the routine for non-linear fitting $n l s$. For $\mathrm{PM}_{2.5}$ the fitted parameters were $a=2.81 \pm 0.05$ and $b=-0.32 \pm 0.01$. The hourly correction factors and the fit to the data are shown in Figure 4.

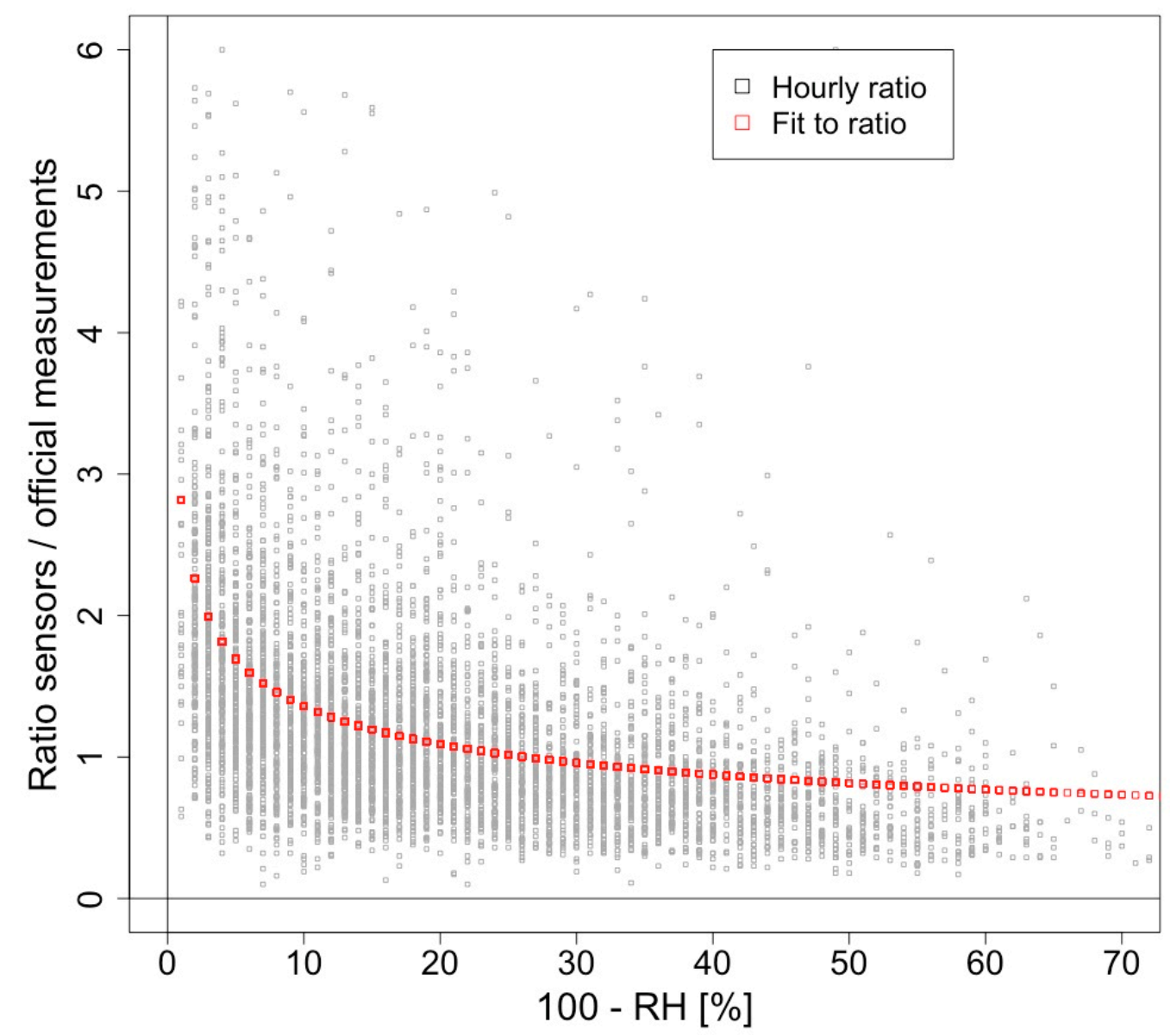

Figure 4. Ratios between the official hourly $\mathrm{PM}_{2.5}$ measurements at Amsterdam Vondelpark and the average of 20 (Nova SDS011) sensors in the center of Amsterdam as a function of (100-RH), where RH is the relative humidity (in \%).

After applying the correction for relative humidity to the data, the correlation between the average of the sensors and the official measurements increases from 0.74 to 0.80 . The result, after correction, is shown in Figure 5. Additionally, the Amsterdam data were used to train and validate a Random Forest (RF) machine-earning algorithm. The results found by us as well as others indicate that RF can further improve the calibration of dust sensors [20].

We have performed similar analyses for the $\mathrm{PM}_{10}$ measurements of the same sensors. On average, the sensors are less sensitive to larger particles. A correction, that includes the separate measurements of $\mathrm{PM}_{2.5}$ and $\mathrm{PM}_{10}$, is able to provide a reasonable correction for the effects of relative humidity. Research into the cause is on-going. 


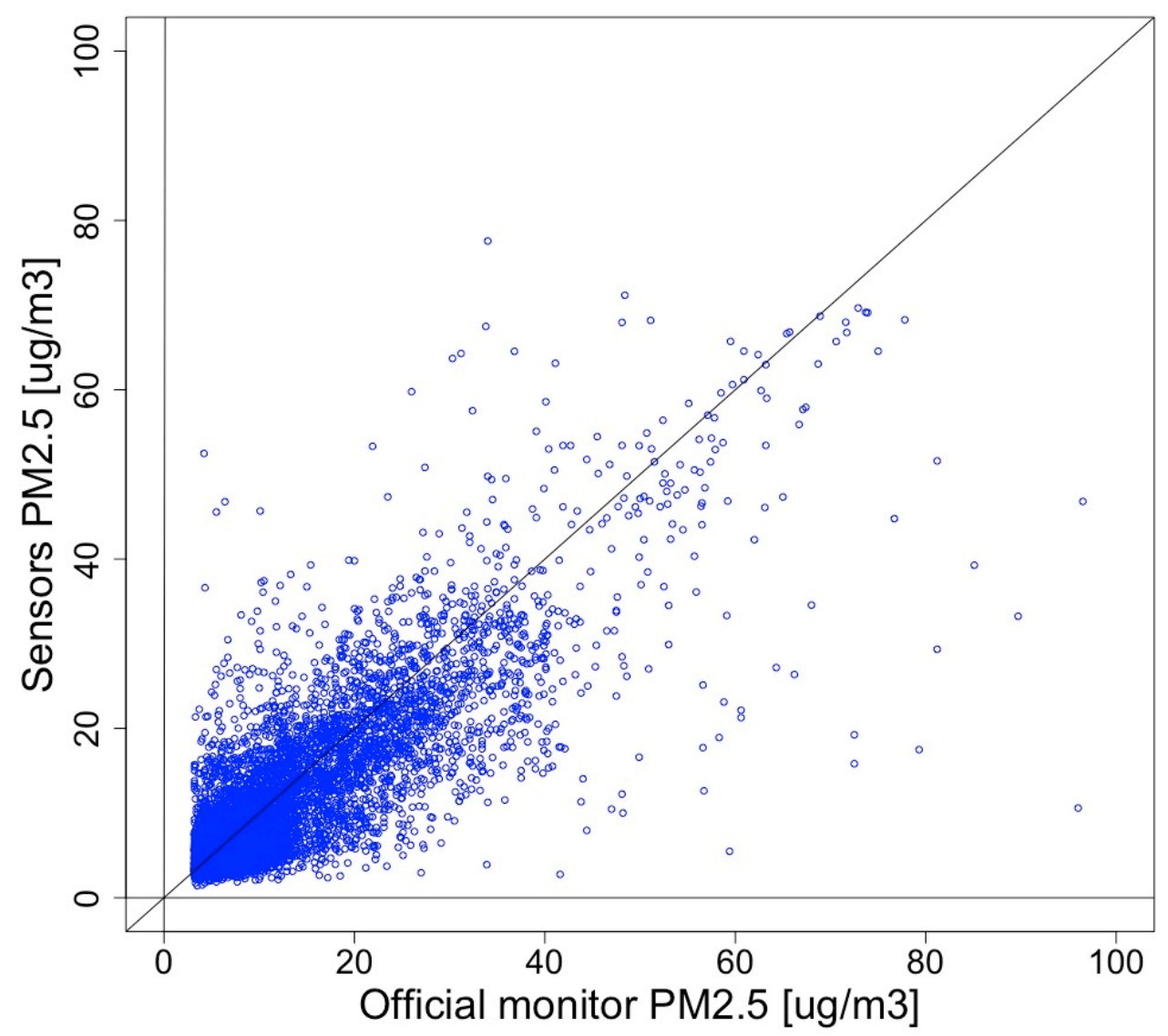

Figure 5. Correlation between the official hourly $\mathrm{PM}_{2.5}$ measurements at Amsterdam Vondelpark (x-axis) and the average of 20 (Nova SDS011) sensors in the center of Amsterdam (y-axis). All concentrations are in $\mu \mathrm{g} / \mathrm{m}^{3}$.

For more tests, around fifteen sensor kits have been deployed along roads on the grounds of Utrecht University, close to RIVM and a partner in several projects. RIVM and Utrecht University manage these sensors. The kits contain the Alphasense $\mathrm{B} 43 \mathrm{~F} \mathrm{NO} \mathrm{NO}_{2}$ sensor and the Nova SDS011 $\mathrm{PM}_{2.5} / \mathrm{PM}_{10}$. The sensor kits at Utrecht University also served as a testing ground to learn more about the housing of several sensors in one kit and, most important, about the best way to communicate the data to the server. The results of these sensors are open to the public and are part of an app that is being developed by students of the University of Utrecht.

\subsection{International Cooperation}

To assess and possibly improve the quality of low-cost sensors, RIVM also contributes to a number of European initiatives:

- With the support of the European Commission's LIFE program, the VAQUUMS project (Various Assessments of air Quality Measurement methods and their policy Support) examines which sensors can be a valuable addition to the reference measurements. It establishes the actual performance of sensor systems measuring particulate matter, ozone and nitrogen dioxide. After a selection of the most promising ones, the sensor systems are subjected to rigorous laboratory and field tests that give insight into their reliability. In the end, an instruction guide for correct sensor usage is to be written. The project also engages a dialogue with local governments, citizens, scientists and industry to define quality requirements for different possible use cases.

- The CEN Technical Committee 264 (Working Group 42: 'Sensors') develops a "Technical Specification" (TS) for air- and PM-based sensor systems. The draft TS so far is based on a combination of field co-location studies and laboratory tests. In the end, the protocol will enable a 
classification of (tested) sensor devices in air quality monitoring for regulatory and non-regulatory purposes (with a lighter experimental design).

- $\quad$ RIVM has also cooperated in the AirSensEUR project organized by the Joint Research Centre (JRC) [21,22]. AirSensEUR boxes have been installed in sites of the national Air Quality Network of the RIVM, generating a large dataset for analysis.

The combined efforts from different (national) institutes, universities and organizations, as well as from many citizen scientists and groups are important to define the general quality parameters of the many sensors that are and will become available. Cooperation is important to obtain useful data on many sensors while still keeping the work required to a reasonable amount. EPAs might play an integrative role here as they are uniquely positioned between authorities, scientists, and citizens.

\section{Integration of Sensor Data with Public and Official Information}

Using sensor data makes it, at least in theory, possible to improve current air quality maps and forecasts of air quality [23]. As a result, the public will be provided with more accurate information about current and future air quality. In this section, we describe the current air quality information provided to the Dutch public and our efforts to improve spatial and temporal resolution of air quality maps, for example by assimilating sensor data.

\subsection{Public Information on Air Quality in the Netherlands}

For environmental information it is not only important to perform measurements, calculations and assessments, it is also important to ensure that the public has full and timely access to this information. It is furthermore important to provide the public with the necessary tools and visualizations to understand the information and to be able to act on it. The Aarhus convention of June 25, 1998 addresses this; "It grants the public rights and imposes on Parties and public authorities obligations regarding access to information and public participation and access to justice" [24]. In the Netherlands, access to real-time accurate information on air quality is provided in several ways. All the measurements of the National Air Quality Monitoring Network (NAQMN) are provided on an hourly basis on a website of RIVM and partners: www.luchtmeetnet.nl. In recent years, the national information system has been extended with real-time maps of hourly air quality, more detailed prognoses and furthermore, all information is available on apps. For the hourly maps, the results of official hourly measurements for $\mathrm{NO}_{2}, \mathrm{PM}_{10}$, $\mathrm{PM}_{2.5}$, and $\mathrm{O}_{3}$ are combined with a set of model runs to create air quality maps with $4 \mathrm{~km} \times 4 \mathrm{~km}$ resolution. Local variations due to emissions from road traffic are modelled separately. The combined result is a detailed air quality map with a resolution of $125 \mathrm{~m} \times 125 \mathrm{~m}$. For the public to be able to act upon air quality, both the present situation and that of the upcoming few days must be available. Several options are available to estimate the air quality for the next few days. The air quality forecast for the Netherlands is based on calculations with the LOTOS-EUROS model [25] run by the Dutch met-office (KNMI).

Presently, all information on air quality is provided on the website www.luchtmeetnet.nl as the official portal to air quality data. All data are also disseminated on a branch of the "Measuring Together" website: https://samenmeten.rivm.nl/uurkaart/. Here the data shown on the website can be combined with other kinds of information, like real-time traffic information, satellite data and results from low-cost sensors. The official $\mathrm{NO}_{2}$ map for the evening of 16 June 2019 is shown as an example (Figure 6).

\section{Example: Use of RIVM Air Quality Maps by Others}

All data created by RIVM for public information is by definition available to other parties. One of the biggest single users of these air quality data is a non-governmental organization, "the Lung Foundation" (in Dutch: "het Longfonds"). This NGO sponsors research about all kinds of lung diseases, and tries to create public awareness for the causes of lung diseases, such as smoking and 
air pollution. A recent activity of the Lung Foundation was to develop an app and website where the public can check the estimated real-time air quality at any location in the Netherlands [26]. By providing a live map, any person, but specifically people with respiratory or lung diseases, can adjust their daily activity accordingly. Within a few months, the app was used more than one million times.

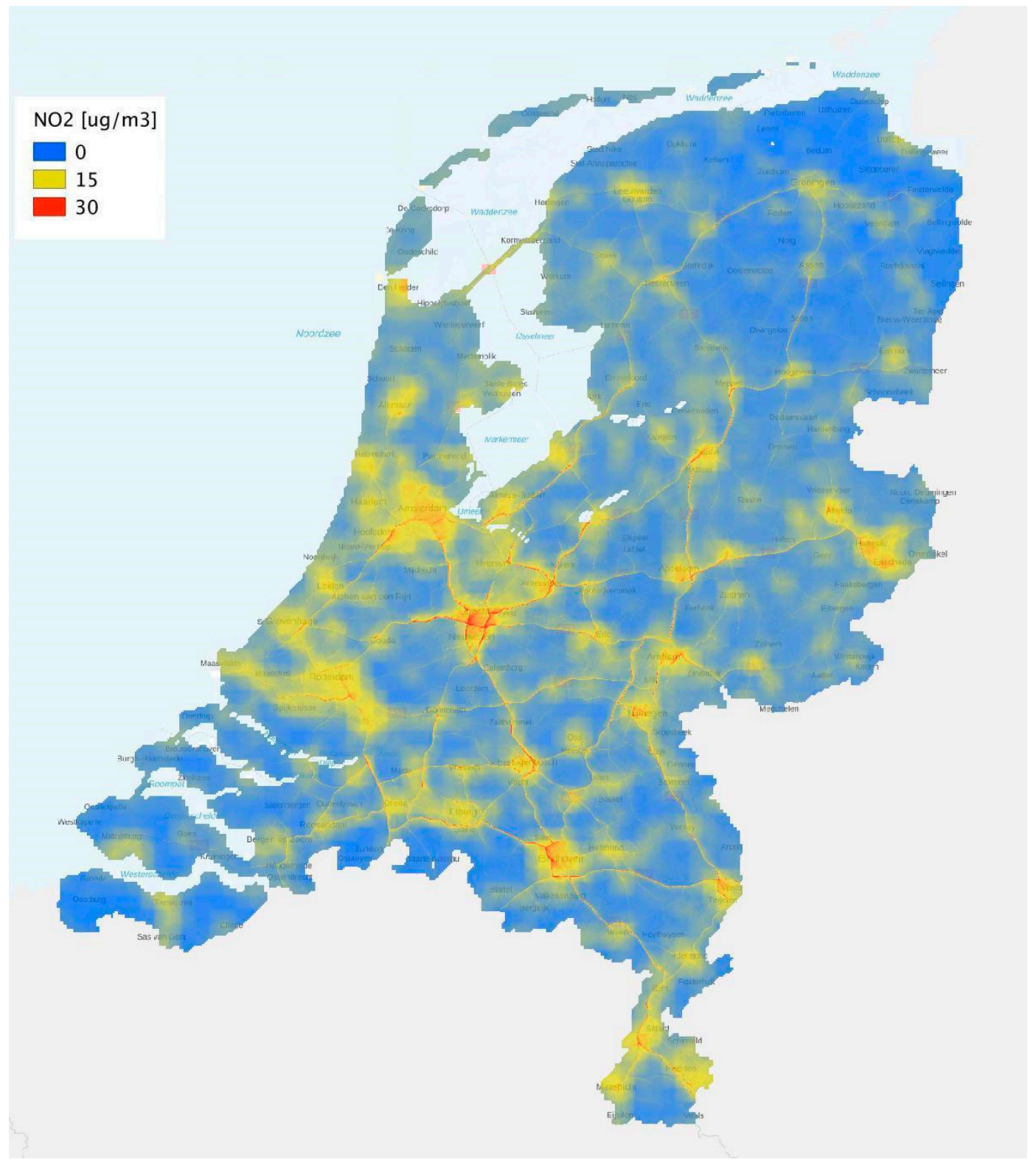

Figure 6. $\mathrm{NO}_{2}$ map presented for the public at 16 June 2019, between 20:00 and 21:00 MET-DST. Blue areas correspond to $\mathrm{NO}_{2}$ concentrations of $0 \mu \mathrm{g} / \mathrm{m}^{3}$ and red areas correspond to $30 \mu \mathrm{g} / \mathrm{m}^{3}$. The map was published on https://samenmeten.rivm.nl/uurkaart/ and on www.luchtmeetnet.nl, shortly after 16 June 2019, 21:00 MET-DST although using different color schemes.

\subsection{Improving Air Quality Maps Using Low Cost Sensor Systems}

One of the next steps to improve information to the public is to combine the increasing number of low-cost $\mathrm{PM}_{10} / \mathrm{PM}_{2.5}$ sensors (roughly 500 in the Netherlands in June 2019) with official measurements and the hourly maps of air quality. To do this, the results of the sensors first have to be corrected for interfering effects, relative humidity being the most important. As discussed in Section 3.2, it has been observed that optical particle counters, i.e. all known low-cost "dust sensors", will report unrealistically 
high $\mathrm{PM}_{2.5}$ and $\mathrm{PM}_{10}$ concentrations when the ambient relative humidity approaches $100 \%$ [27]. For well-known sets of sensors, like those in Amsterdam, a dedicated calibration over a longer period is possible. In many cases, however, sensors appear on the data portal without any prior knowledge about the quality and/or sensitivity to humidity. Therefore, an on-the-fly approach is necessary. Two mechanisms for on-the-fly calibration of PM sensors are presently tested and implemented at RIVM: 1. Calibration using a separately determined calibration curve based on ambient humidity and 2 . Calibration using ratios between results of official measurements and groups of nearby sensors.

For method 1, a calibration curve must be determined. In some cases, sensors can be calibrated over a substantial period near or at an official measurement station, like discussed in Section 3. In general, a relation for calibration can be estimated by comparing the average results of a group of sensors to results of co-located, or very close by, official measurements. This calibration determined at one location is assumed to be applicable for other sensors (of the same type) at nearby similar locations. This seems a reasonable assumption as groups of co-located SDS011 sensors show quite similar behavior in practice, and since relative humidity is the main factor for the calibration. There are, of course variations in the responses of individual sensors, leading to uncertainties in the assumed calibration. Given a parameterization of the calibration of the sensors, a map of known relative humidity's can be used to construct a map of corrections for the sensors. The Dutch met-office runs a network of approximately 30 measuring stations, providing real time meteorological data that are used in the analysis and calibration of the sensors. Many sensor kits are equipped with their own temperature and humidity sensor that can, in principle, be used as input for the calibration curve. Unfortunately, these low-cost sensors break down frequently and are therefore not a solid base for calibration. Using the data from the Dutch met-office may introduce an uncertainty in the calibration as the conditions are rarely measured very close to the location of the sensors. On the other hand, relative humidity changes slowly within an area and the accuracy and stability of the official meteorological data is very good.

Method 2 is similar, but does not rely on meteorological data. In several tests with groups of sensors in Dutch cities, it was observed that the differences between results of sensors within these groups are quite small. Although there are many sources of particulate matter in urban areas, the local impact is usually quite limited, in the Netherlands. On average, road traffic contributes only 1-2 $\mu \mathrm{g} / \mathrm{m}^{3}$ to the $\mathrm{PM}_{10}$ concentration, and even less to $\mathrm{PM}_{2.5}$. Wood burning might be another local source of PM pollution. Nonetheless, depending on the meteorological conditions, the plumes resulting from wood burning will meander. This does not lead to consistently high local contributions, unless measurements are taken very close to chimneys or when several chimneys surround the location. An option is therefore to compare the average of the sensors located within several kilometers of an official measuring station to the result of this official measurement. The ratio of sensors versus official measurements can be used as a local correction factor for all similar sensors in the area. The results of a number of these ratios can be interpolated all over the Netherlands to create a correction field for the sensors. Tests are ongoing to establish the uncertainties of the different options for a nationwide on-the-fly calibration of dust sensors.

Example: tracking high PM concentrations following Easter bonfires

Another activity where we used fine-grained sensor data to improve real-time air quality maps, was tracking bonfires' dust during Easter 2019. The tradition of having large bonfires is very common in several countries in Europe. Depending on the meteorological conditions, the effects of these fires can be observed in a large downwind area. Especially the smell of the fires is observed far away from the fires. In 2019, a long period of draught preceding Easter caused strong concerns about the fires. As a result, most of the bonfires in the Netherlands were cancelled. In Germany, however, the situation was different and many fires were lighted, mainly on the evening before Easter. As the wind came from the east at that time, the plumes of the fires slowly moved to the Netherlands. The dust in the plumes consisted mainly of $\mathrm{PM}_{2.5}$. Because of the availability of approximately 45 official $\mathrm{PM}_{10} / \mathrm{PM}_{2.5}$ 
measuring stations, in combination with 350 dust sensors, mostly SDS011, RIVM was able to make a detailed map of the cloud of dust as it built up along the eastern border and then slowly moved over the country, to the west (Figure 7). Concentration maps were generated for every hour of the Easter weekend and combined into a video clip that was subsequently shared with the public [28].

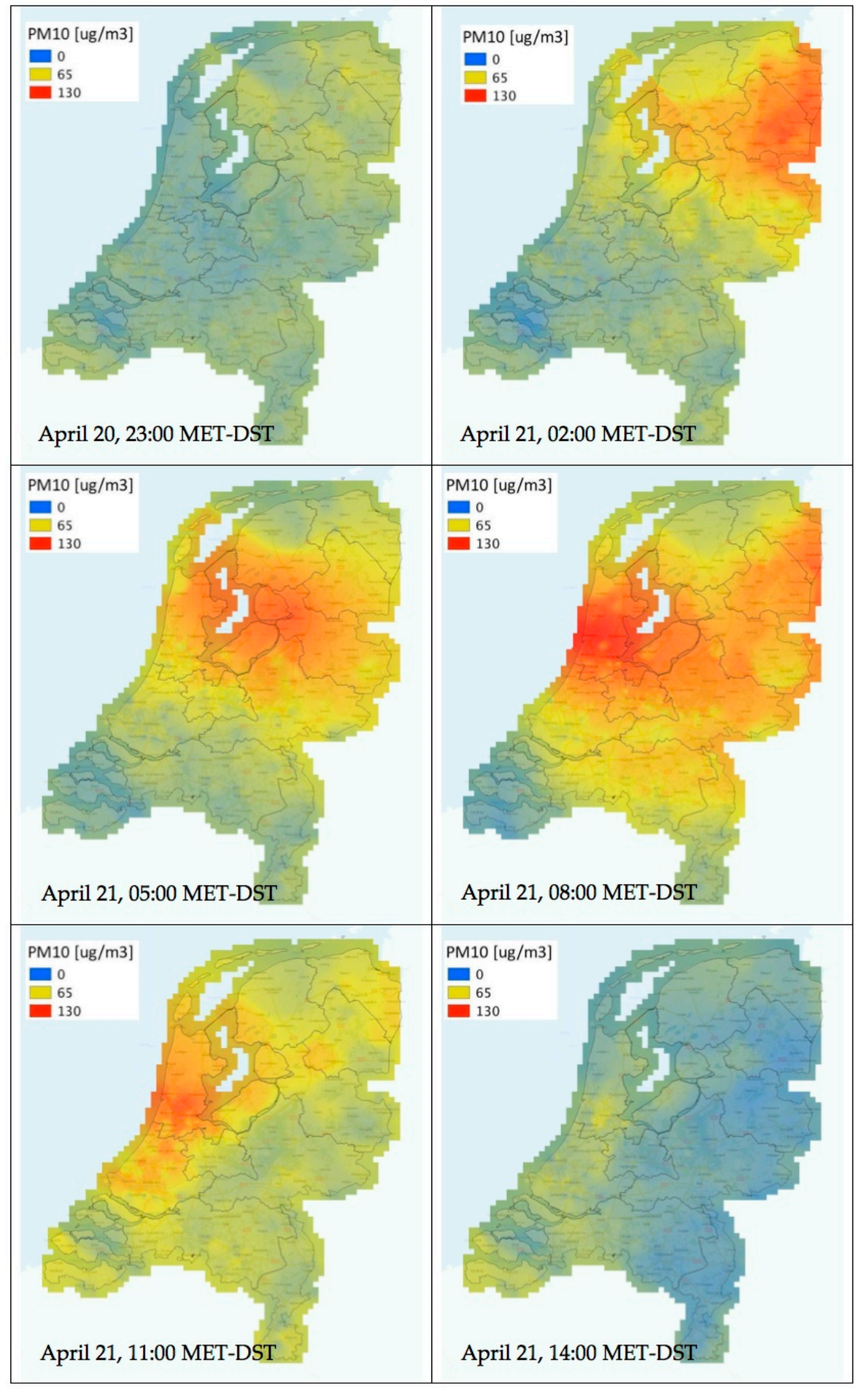

Figure 7. Maps of the dust cloud moving over the Netherlands during Easter 2019, using information from 45 official measuring stations and some 350 dust sensors. The dust in the plumes consisted mainly of $\mathrm{PM}_{2.5}$. Blue colors indicate $0 \mu / \mathrm{m}^{3}$, red indicates $130 \mu \mathrm{g} / \mathrm{m}^{3}$. From top-left to right-bottom, the maps are for 20 April, 23:00 until 21 April, 14:00, in steps of $3 \mathrm{~h}$. 


\section{Data Portal}

An important request from citizen scientists is the possibility to see their own sensor data, and to compare their own measurements to other sensors or official reference measurements. Therefore, RIVM has developed a data portal where sensor data are publicly available: samenmeten.rivm.nl. To our knowledge, this data portal represents the most comprehensive and continuously increasing sensor dataset in the Netherlands, currently comprising over 500 sensors.

Everyone is encouraged to share air quality sensor data with RIVM. However, RIVM has a few requirements for sharing to improve data quality, including:

- Type of sensor and modifications (for instance "air drying") must be known. This is important in order to assess the quality of the data and to decide whether to include the sensor data in RIVM's calibration algorithms.

- All algorithms used to calibrate and post-process the data of sensors should be known; no "black boxes" are allowed. The use of proprietary algorithms in sensors is inevitable. However, subsequent treatment of the data by the producer or by the user should be reported and documented.

- The owner of the sensor should be aware that the data will be made publicly available and that his or her location is shared on a map. The location of the sensors is randomly shifted by up to 50 meters every time they are shown on a map. This makes it more difficult for casual users of the website to establish the exact location of the sensor and thus provides a certain level of privacy for people who share their sensor data.

\subsection{Data Acquisition and Storage}

RIVM collects sensor data from a variety of its own projects, using multiple IoT techniques, such as Wi-Fi, LoRa, and Narrowband (NB-IoT), to harvest these data. Experiences with these techniques have been varied. Wi-Fi has been used by RIVM to upload the sensor data since the early days. The main drawback of Wi-Fi-connectivity is the number of operations required from the user. Technically skilled users generally have no problem connecting the sensor to their own Wi-Fi-network, but it proves difficult for others. Moreover, the Wi-Fi signal is more prone to failure especially when used with mobile networks $(3 / 4 \mathrm{G})$, leading to messed-up or missing data. Therefore, other sensors are equipped with LoRa, provided by The Things Network (TTN) [29]. LoRa requires a simpler configuration than Wi-Fi and delivers a more robust data stream. Data are read via the Message Queuing Telemetry Transport (MQTT), a straightforward protocol to harvest the data from TTN. The main drawback of LoRa is the lack of coverage in rural areas. Consequently, it is not possible to use LoRa for monitoring in rural areas except when own gateways are deployed, which is not practical for RIVM. NB-IoT is increasingly being used as a communication technique to transmit sensor data. NB-IoT uses the existing commercial mobile networks to connect devices and servers. A major advantage is that it has nation-wide coverage, at least in the Netherlands. All data land in an InfluxDB, a relatively simple database optimized for time series and fast access to the data.

Some sensor data are collected from other projects' API's using Python. For example, Luftdaten has several thousand sensors operational in Europe, and offers the data by an open API. Every five minutes, an API-call is performed to collect data from devices in the Netherlands, Belgium and Germany.

As a result, InfluxDB holds all raw data records from various sources. However, InfluxDB is regarded as a pass-through-database, and all raw data are near real-time inserted into a PostgresDB. This PostgresDB is within the RIVM-firewall and considered as the primary database. In PostgresDB, the raw data are accumulated into hourly averages. These hourly averages are, sometimes after calibration, visualized at RIVM data portal. 


\subsection{Visualization and Downloads}

RIVM data portal shows sensors as colored dots on the map, with colors based on the most recent hourly sensor value (Figure 8). The color scale that is used is based on color scales used in other Dutch air quality maps, such as those at the Atlas of the Living Environment [30]. Sensor data are shown for different air quality components: $\mathrm{PM}_{10}, \mathrm{PM}_{2.5}$, and $\mathrm{NO}_{2}$. In addition to sensor data, monthly data from passive $\mathrm{NO}_{2}$ samplers are also visualized. When available, weather data such as temperature and air pressure, can also be selected.

As a result, the homepage of the RIVM data portal provides a rapid overview of the current air quality in the Netherlands, as measured by all sensors. It is possible to zoom in to municipal or individual sensor level. When ten or fewer sensors are visible, a dashboard pops up with a line graph for all sensors, making it possible to get a quick impression of the trends from these sensors (Figure 9). Moreover, it is possible to examine individual sensor data. By default, a time series plot is shown, where sensor data can be compared to the nearest official reference air quality station. Time series data are useful to learn about the variability in air pollution concentrations.

All sensor data are available for download. Currently, an application-programming interface (API) is being developed using the OGC SensorThings API [31], making it easy for third parties to download sensor data in bulk. For people who are not familiar with APIs, a new download function will be developed.

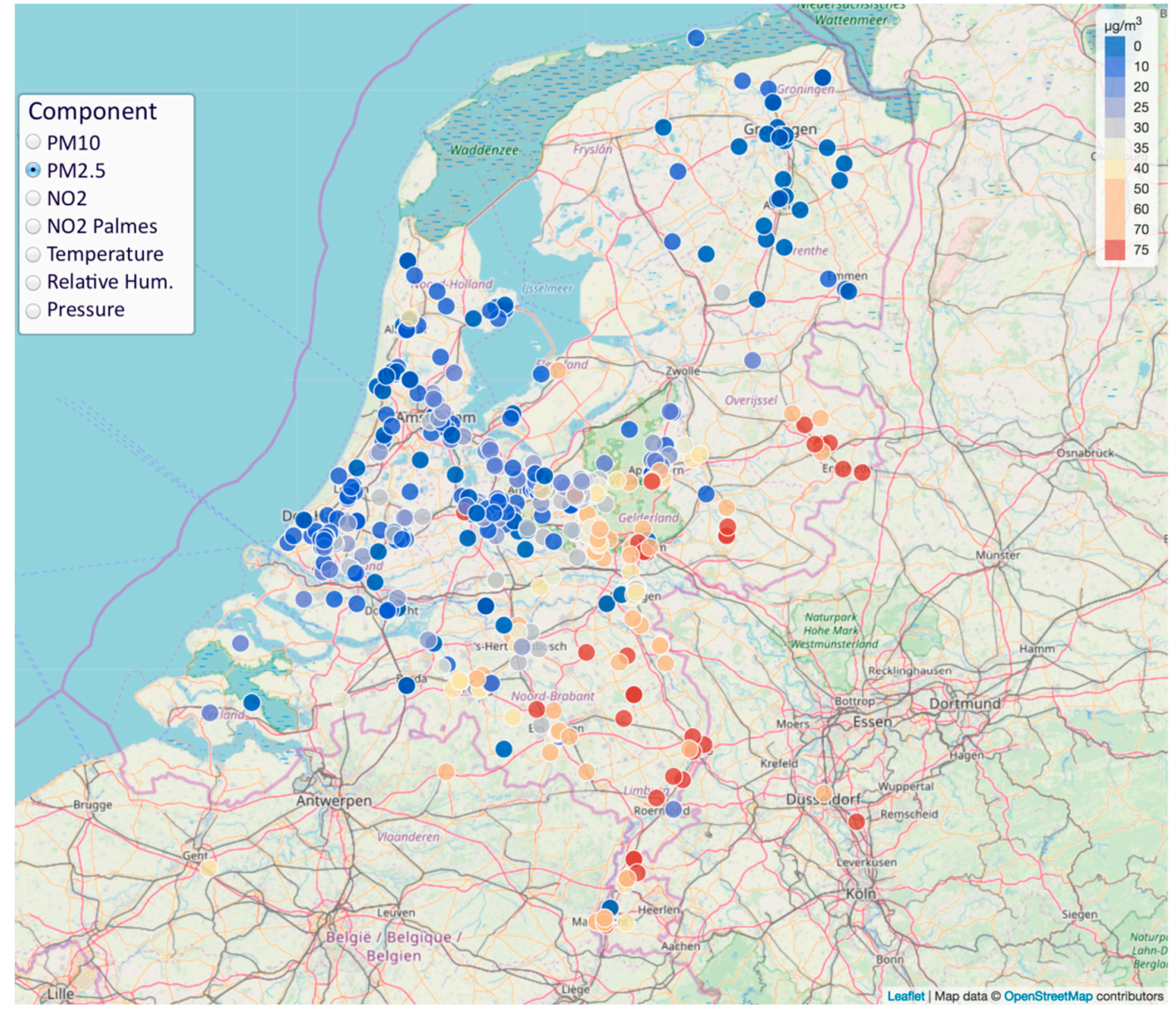

Figure 8. View of the "Measuring Together" data portal (samenmeten.rivm.nl), example from 26 June, 2019, when the figure was shown on the data portal. The sensors displayed on the portal show higher $\mathrm{PM}_{2.5}$ concentration in the southeast of the country. The official measurements showed the same pattern. 


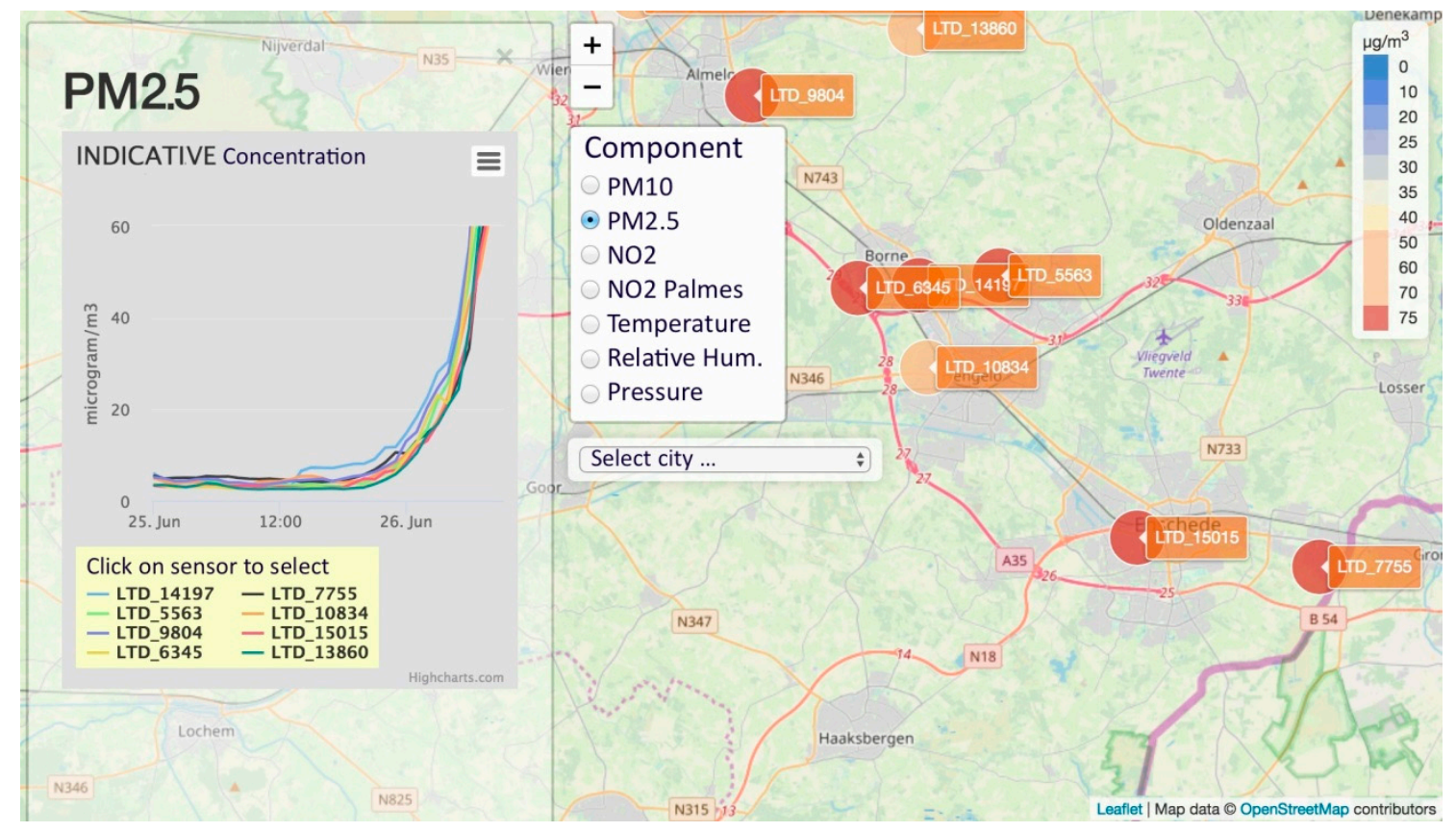

Figure 9. View of the "Measuring Together" data portal (samenmeten.rivm.nl) after zooming to almost street level, example from 26 June 2019, when the figure was shown on the data portal. The individual results of all sensors in the view (when less than 10) are presented. The eight sensors shown in the left panel all show strongly increasing $\mathrm{PM}_{2.5}$ concentrations over the last $12 \mathrm{~h}$.

\section{Discussion}

The development of a national data platform for sensor data opens up opportunities to integrate data from national or global sources, which may lead to the development of data products and applications that can help users understand air quality at neighborhood scale [32]. Here we have presented RIVM's approach for developing such a data platform and presented some use case examples. Historically, air quality data has been collected by several communities, researchers, and academics, but often only in the context of individual programs. A centralized data platform is therefore an important wish of the air quality community, as it allows a more efficient collection and visualization of sensor data, and allows for more powerful data analytics [32]. For instance, calibration algorithms can be tested on a large scale, in real-world situations. Moreover, by providing a data platform, individuals do not need to solve problems like data connection, data acquisition and visualization of sensor data, but can focus on the results of their measurements.

In a recent workshop on low-cost air quality sensors, it was discussed that the air quality community needs to move away from qualifying sensor data as good or bad, because it will be up to the end-users to determine whether the data quality is good enough for their particular use [32]. An important precondition for this is the inclusion of metadata so that the quality of the sensor data can be characterized. This will be an important next step for RIVM's data platform as metadata is currently not automatically included. For well-known projects, such as Luftdaten and RIVM's own projects, the set-up of the sensor is known, but individual sensor modifications might happen. This should be included in the metadata but individual users typically do not supply metadata. A standardized method of collecting metadata will thus be important. Consequently, calibration algorithms developed by RIVM only make use of well-known sensors, such as the SDS011 and B43F and in a few months, the Sensirion SPS30 will also be included. All this implies that the maintenance and quality assurance of the air quality monitoring system will undergo fundamental changes if sensors are to become part of the regular monitoring system.

Even though the quality of sensor data might be sufficient for certain applications, it remains important to put the use of low-cost sensors into perspective: the current quality of low-cost sensors 
does not allow using the data for legal purposes or to test against air quality standards. Moreover, analyzing individual sensor data might not be useful because of the variability in sensor quality. At the same time, as the examples in our article show, the use of low-cost sensors, particularly of PM-sensors, can add value to the regular monitoring system as well as to individual users' experience, and can generate attention to air quality issues in general, consistent with typical examples from the literature [33]. Therefore, it is important to strike the right balance between promoting the use of sensors and questioning the value of (individual) sensors. This remains an on-going challenge, particularly with the rise of commercial companies claiming sensor data can be used for policy decision-making [34]. Moreover, the involvement of hundreds of individuals and dozens of city councils, each with their own ideas about the use of air quality sensors, makes it practically impossible to emphasize this to individuals. The establishment of a knowledge portal where current information about air quality sensors is shared helps to facilitate discussions about the quality of sensor data, and to clarify expectations at the start of projects. Moreover, expanding our presence on social media makes it easier to participate in direct discussions with non-professionals.

The involvement of citizens requires a shift in approach from air quality experts from targeting only other professionals in the field towards also engaging with non-professionals. In many cases, citizens are interested in the consequences of air pollution for their own health, and ask for effective ways to tackle air pollution in their neighborhood; issues that are traditionally somewhat out of the scope of experts on environmental data. In addition, since current sensors do not meet objective quality requirements, linking sensor data to health outcomes is tricky. This implies that it may not be possible to address all concerns raised by citizens, though it may be useful to raise awareness about the potential health impacts of air pollution. Therefore, a reflexive approach from air quality experts is required, where concerns from citizens are taken serious, but limitations of current technologies are clearly explained.

Lastly, the involvement of EPAs in sensors and air quality is important to standardize practices, both nationally as well as internationally. Therefore, RIVM is actively involved in, for instance, the CEN Technical Committee. Moreover, the involvement of EPAs from many countries should ensure that the measurements of air quality are carried out in a transparent way, and that open data are safeguarded. This is particularly important since the concept of a 'smart city' is of interest to a wide range of commercial parties, and several companies, such as Google, are now starting to measure air quality as a service to governments [35]. At the same time, RIVM's data platform allows third parties to monetize the data. For instance, data might be used for apps such as a route planner based on the lowest air pollution exposure, dashboards about the local environment et cetera. An important concern here is that of environmental justice [32], as this might not benefit the data owners who contributed data to the data platform. However, these developments might also advance science and practical, real-world application of air quality data. Nonetheless, it is important that air quality data, but also the subsequent tools to analyze the data, are available to local communities that may lack the skills or resources to develop these tools themselves. Therefore, an active role of EPAs will make sure that data about the living environment will remain freely available for citizens.

\section{Outlook}

So far, we have reflected on the experiences resulting from our "Innovation Program for Environmental Monitoring". The next steps within the program include the assimilation of other types of air quality information, such as satellite data, into the hourly air quality maps (Figure 1). Another important step is the move towards a better characterization of individuals' air pollution exposure during the day. Presently, epidemiological studies often link health outcomes to air pollution at the home address, while a significant amount of time is spent elsewhere. Sensors allow a better quantification of actual exposure to air pollution [36]. Currently, RIVM is involved in a project where Sensirion SPS30 dust sensors are being mounted on 500 bicycles, all located within some $25 \mathrm{~km}$ from the city of Utrecht. Calibration and validation of the output will be a major challenge, but if successful, a 
better estimation of typical air pollution during cycle commutes will be obtained. Sensors are also being deployed around intensive livestock farming, where a potential link between actual PM-concentrations and short-term health outcomes will be investigated. These projects represent steps towards the overall aim to better quantify the exposome, i.e. all environmental exposures of an individual in a lifetime, and how those exposures relate to health.

In future, the system with sensors that we are building could be further expanded to also include the exposure at the own home or other indoor environments. This however requires ways to deal with privacy issues, as will the use of personal measurements e.g. with activity trackers and the like. Also, addition of other environmental parameters (e.g., noise, radiation) would be a possibility.

\section{Conclusions}

The role of EPAs will change significantly over the coming years because of the rise of citizen science and increasingly better performing low-cost sensor technology. As our article shows, a knowledge portal and a centralized data platform are important tools to connect with citizens and their respective needs, and to facilitate the sharing of air quality data obtained by low-cost sensors. Providing the public with the information needed to perform better measurements is mutually beneficial for the citizens and EPA's. Other EPA's and similar organizations are recommended to create their own versions of these kinds of portals or provide similar services using other tools and solutions.

It is important that the data in the portal are "open" and the data platform and subsequent tools are accessible to all, and that it is easy for third parties to up- and download their data. For the majority of users of the data portal, visualization of sensor data is most useful when it shows current air quality and indicates whether the level of air pollution is 'high' or 'low'.

Providing some sort of calibration standard or methods is important to increase the overall quality of the sensor data in the portal. A centralized data platform allows for better data analytics and the establishment of shared calibration algorithms. An important precondition for this is the inclusion of sufficient metadata so that the sensor quality can be characterized. Further research is needed to establish robust calibration methods and to better understand citizen scientists' needs to improve the current data platform.

Many of the users of the Dutch platforms look for information about the relation between their health and the air pollution they measure. Given the current quality of sensor measurements, establishing explicit links between sensor results and health effects is tricky. It is very important to communicate the uncertainties and limitations of sensors clearly. In our experience, users of sensor data understand the limitations of their measurement results.

Finally, for national EPA's and similar organizations, an important task is to remain an independent and impartial judge of air quality findings, irrespective of whether these are obtained by official measurements or by new sensor technology. By doing this, the EPA's can earn and keep the trust of all involved parties, citizens, as well as authorities.

Author Contributions: All authors are part of the 'Measuring Together'/'Samen Meten' team at RIVM, and contributed to (parts of) the work described in this article. Conceptualization, J.W.; Writing-original draft, J.W. and H.d.R.; Writing-review and editing, J.W., H.d.R., C.B., D.D., E.W., H.V., J.V., L.G., M.V., P.Z., S.v.R., and E.T. All authors approved the final version.

Funding: The "Innovation Program for Environmental Monitoring" is funded by the Dutch Ministry of Infrastructure and Water Management.

Acknowledgments: We acknowledge all citizen scientists who have contributed their sensor data and knowledge to us. In particular, we would like to acknowledge Teus Hagen and Dieter Pientka. Furthermore, we would like to express our gratitude to representatives from several Dutch cities who started experimenting with sensors for air quality and to the (inter)national organizations working with us on this topic. Lastly, we gratefully acknowledge funding and support from the Dutch Ministry of Infrastructure and Water Management.

Conflicts of Interest: The authors declare no conflict of interest. 


\section{References}

1. EEA. Air Quality in EUROPE—2015 Report; Publications Office of the European Union: Luxembourg, 2015. [CrossRef]

2. Commission Directive. 96/62/EC of 27 September 1996 on Ambient Air Quality Assessment and Management; Publications Office of the European Union: Brussels, Belgium, 2008.

3. European Commission. Directive 2008/50/EC of the European Parliament and of the Council of 21 May 2008 on ambient air quality and cleaner air for Europe. Off. J. Eur. Union 2008, 152, 1-44.

4. Mead, M.; Popoola, O.; Stewart, G.; Landshoff, P.; Calleja, M.; Hayes, M.; Baldovi, J.; McLeod, M.; Hodgson, T.; Dicks, J.; et al. The use of electrochemical sensors for monitoring urban air quality in low-cost, high-density networks. Atmos. Environ. 2013, 70, 186-203. [CrossRef]

5. Moltchanov, S.; Levy, I.; Etzion, Y.; Lerner, U.; Broday, D.M.; Fishbain, B. On the feasibility of measuring urban air pollution by wireless distributed sensor networks. Sci. Total Environ. 2015, 502, 537-547. [CrossRef] [PubMed]

6. Snyder, E.G.; Watkins, T.H.; Solomon, P.A.; Thoma, E.D.; Williams, R.W.; Hagler, G.S.W.; Shelow, D.; Hindin, D.A.; Kilaru, V.J.; Preuss, P.W. The Changing Paradigm of Air Pollution Monitoring. Environ. Sci. Technol. 2013, 47, 11369-11377. [CrossRef] [PubMed]

7. Jiang, Q.; Kresin, F.; Bregt, A.K.; Kooistra, L.; Pareschi, E.; Van Putten, E.; Volten, H.; Wesseling, J. Citizen Sensing for Improved Urban Environmental Monitoring. J. Sens. 2016, 2016, 1-9. [CrossRef]

8. Luftdaten. Available online: www.luftdaten.info (accessed on 17 June 2019).

9. Castell, N.; Dauge, F.R.; Schneider, P.; Vogt, M.; Lerner, U.; Fishbain, B.; Broday, D.; Bartonova, A. Can commercial low-cost sensor platforms contribute to air quality monitoring and exposure estimates? Environ. Int. 2017, 99, 293-302. [CrossRef] [PubMed]

10. Volten, H.; Devilee, J.; Apituley, A.; Carton, L.; Grothe, G.; Keller, C.; Kresin, F.; Land-Zandstra, A.; Noordijk, E.; van Putten, E. Chapter 21 in Enhancing National Environmental Monitoring through Local Citizen Science; UCL Press: London, UK, 2018.

11. Samen Meten. Status of Air Quality Sensors and Their Use in (official) Monitoring Strategies. Available online: https://www.samenmetenaanluchtkwaliteit.nl/sensor-meeting-february-13th-2017 (accessed on 17 June 2019).

12. Nova. Laser PM2.5 Sensor-SDS011. Available online: http://inovafitness.com/en/a/chanpinzhongxin/95. html (accessed on 18 June 2019).

13. Alphasense. Nitrogen Dioxide-Alphasense 4-Electrode gas sensors operate using proven fuel technology. Available online: http://www.alphasense.com/index.php/products/nitrogen-dioxide-2/ (accessed on 18 June 2019).

14. R Development Core Team. R: A Language and Environment for Statistical Computing; R Foundation for Statistical Computing: Vienna, Austria, 2011.

15. Team RStudio. RStudio: Integrated Development for R.; RStudio, Inc.: Boston, MA, USA, 2015; p. 14.

16. Tsujita, W.; Yoshino, A.; Ishida, H.; Moriizumi, T. Gas sensor network for air-pollution monitoring. Sens. Actuators B Chem. 2005, 110, 304-311. [CrossRef]

17. van den Elshout, S.; Willers, S.; van der Gaag, E. Duurtest NO2-sensor (Testing NO2-sensor). Lucht 2019, 2, 15-19.

18. Jayaratne, R.; Liu, X.; Thai, P.; Dunbabin, M.; Morawska, L. The influence of humidity on the performance of a low-cost air particle mass sensor and the effect of atmospheric fog. Atmos. Meas. Tech. 2018, 11, 4883-4890. [CrossRef]

19. De Jonge, D. Correction factors Met-One BAM1020 PM10 and PM2.5 over 2018; Public Health Service (GGD): Amsterdam, The Netherlands, 2019. (In Dutch)

20. Zimmerman, N.; Presto, A.A.; Kumar, S.P.N.; Gu, J.; Hauryliuk, A.; Robinson, E.S.; Robinson, A.L.; Subramanian, R. A machine learning calibration model using random forests to improve sensor performance for lower-cost air quality monitoring. Atmos. Meas. Tech. 2018, 11, 291-313. [CrossRef]

21. Gerboles, M.; Spinelle, L.; Kotsev, A.; Signorini, M.; Srl, L. Airsenseur: An open-designed multi-sensor platform for air quality monitoring. In Proceedings of the Fourth Scientific Meeting EuNetAir, Linkoping, Sweden, 3-5 June 2015; pp. 3-5. 
22. Kotsev, A.; Schade, S.; Craglia, M.; Gerboles, M.; Spinelle, L.; Signorini, M. Next Generation Air Quality Platform: Openness and Interoperability for the Internet of Things. Sensors 2016, 16, 403. [CrossRef] [PubMed]

23. Castell, N.; Dauge, F.R.; Lahoz, W.A.; Schneider, P.; Vogt, M.; Bartonova, A. Mapping urban air quality in near real-time using observations from low-cost sensors and model information. Environ. Int. 2017, 106, $234-247$.

24. McAllister, S.T. The Convention on Access to Information, Public Participation in Decision-Making, and Access to Justice in Environmental Matters. Colo. J. Int. Environ. Law Policy V 1999, 10, 187.

25. Manders, A.M.; Builtjes, P.J.; Curier, L.; van der Gon, D.; Hugo, A.; Hendriks, C.; Jonkers, S.; Kranenburg, R.; Kuenen, J.J.; Segers, A.J. Curriculum vitae of the LOTOS-EUROS (v2. 0) chemistry transport model. Geosci. Model Dev. 2017, 10, 4145-4173. [CrossRef]

26. Lung Foundation. Hoe Gezond Is de Lucht bij Jou? (How clean is your air?). Available online: https: //www.longfonds.nl/gezondelucht/ (accessed on 17 June 2019).

27. Liu, H.-Y.; Schneider, P.; Haugen, R.; Vogt, M. Performance Assessment of a Low-Cost PM2.5 Sensor for a near Four-Month Period in Oslo, Norway. Atmosphere 2019, 10, 41. [CrossRef]

28. RIVM. PM10 over the Netherlands due to Easter Fires in Germany. Available online: https://www.rivm.nl/nieuws/verhoogde-fijnstofconcentraties-op-eerste-paasdagandEmbeddedVideohttps: //www.rovid.nl/rivm/aco/2019/rivm-aco-20190423-id2ilv1f5-web-hd.mp4 (accessed on 14 June 2019).

29. The Things Network. Available online: https://www.thethingsnetwork.org/ (accessed on 18 June 2019).

30. Atlas Leefomgeving. Available online: https://www.atlasleefomgeving.nl/kaarten (accessed on 14 June 2019).

31. Liang, S.; Huang, C.-Y.; Khalafbeigi, T. OGC SensorThings API Part 1: Sensing, Version 1.0.; Open Geospatial Consortium: Wayland, MA, USA, 2016.

32. Clements, A.L.; Griswold, W.G.; Rs, A.; Johnston, J.E.; Herting, M.M.; Thorson, J.; Collier-Oxandale, A.; Hannigan, M. Low-Cost Air Quality Monitoring Tools: From Research to Practice (A Workshop Summary). Sensors 2017, 17, 2478. [CrossRef] [PubMed]

33. Morawska, L.; Thai, P.K.; Liu, X.; Asumadu-Sakyi, A.; Ayoko, G.; Bartoňová, A.; Bedini, A.; Chai, F.; Christensen, B.; Dunbabin, M.; et al. Applications of low-cost sensing technologies for air quality monitoring and exposure assessment: How far have they gone? Environ. Int. 2018, 116, 286-299. [CrossRef] [PubMed]

34. Lewis, A.; Edwards, P. Validate personal air-pollution sensors. Nature 2016, 535, 29-31. [CrossRef] [PubMed]

35. Apte, J.S.; Messier, K.P.; Gani, S.; Brauer, M.; Kirchstetter, T.W.; Lunden, M.M.; Marshall, J.D.; Portier, C.J.; Vermeulen, R.C.; Hamburg, S.P. High-Resolution Air Pollution Mapping with Google Street View Cars: Exploiting Big Data. Environ. Sci. Technol. 2017, 51, 6999-7008. [CrossRef] [PubMed]

36. Jerrett, M.; Donaire-Gonzalez, D.; Popoola, O.; Jones, R.; Cohen, R.C.; Almanza, E.; De Nazelle, A.; Mead, I.; Carrasco-Turigas, G.; Cole-Hunter, T.; et al. Validating novel air pollution sensors to improve exposure estimates for epidemiological analyses and citizen science. Environ. Res. 2017, 158, 286-294. [CrossRef] [PubMed]

(C) 2019 by the authors. Licensee MDPI, Basel, Switzerland. This article is an open access article distributed under the terms and conditions of the Creative Commons Attribution (CC BY) license (http://creativecommons.org/licenses/by/4.0/). 